\title{
Rendimento de grãos de soja em função de diferentes sistemas de manejo de solo e de rotação de culturas
}

\author{
Soybean yield associated to different soil tillage methods and crop rotations systems
}

\author{
Henrique Pereira dos Santos ${ }^{1}$ Julio Cesar Barreneche Lhamby ${ }^{2}$ \\ Silvio Tulio Spera
}

\section{RESUMO}

O objetivo do presente trabalho foi avaliar sistemas de manejo de solo e de rotação de culturas sobre o rendimento de grãos e componentes do rendimento de soja durante seis anos. Foram comparados quatro sistemas de manejo de solo - 1) plantio direto, 2) cultivo mínimo, no inverno e semeadura direta, no verão, 3) preparo convencional de solo com arado de discos, no inverno e semeadura direta, no verão e 4) preparo convencional de solo com arado de aivecas, no inverno e semeadura direta, no verão - e três sistemas de rotação de culturas: sistema I (trigo/soja), sistema II (trigo/soja e ervilhacal milho ou sorgo) e sistema III (trigo/soja, ervilhaca/milho ou sorgo e aveia branca/soja). $O$ delineamento experimental foi de blocos ao acaso, com parcelas subdivididas e três repetições. $O$ rendimento de grãos e o peso de 1.000 grãos de soja cultivada sob plantio direto e sob cultivo mínimo foi superior ao de soja cultivada sob preparo convencional de solo com arado de discos e com arado de aivecas. A maior estatura de plantas de soja ocorreu no plantio direto. $O$ rendimento de grãos de soja cultivada após trigo, no sistema II, foi superior ao de soja cultivada após aveia branca e após trigo, no sistema III, e após trigo, no sistema I. O menor rendimento de grãos, peso de grãos por planta de soja e peso de 1.000 grãos ocorreu quando em monocultura (trigo/soja).

Palavras-chave: sucessão de culturas, preparo convencional de solo, cultivo mínimo, plantio direto, componentes do rendimento.

\section{ABSTRACT}

The objective of this six-year study was to assess the soil tillage systems and crop rotation systems on soybean grain and yield components were evaluated at Embrapa Trigo in Passo Fundo, RS, Brazil. Four soil tillage systems - 1) no- tillage, 2) minimum tillage in winter and no-tillage in summer, 3) conventional tillage with disk plow in winter and no-tillage in summer, and 4) tillage using a moldboard plow in winter and no-tillage in summer - and three crop rotation systems [system I (wheat/soybean), system II (wheat/soybean and common vetch/corn or sorghum), and system III (wheat/ soybean, common vetch/corn or sorghum and white oats/ soybean)]. An experimental randomized blocks design, with split-plots and three replications, was used. The yield and weight of 1,000 kernels of soybean grown under no-tillage and minimum tillage was higher than soybean grown conventional soil tillage with disk plow and a moldboard plow. Plant height showed higher in the no-tillage. The yield of soybean grown after wheat, in system II, was higher than soybean grown after white oats and after wheat, in system III, and after wheat, in system I. The lowest soybean yield, grain weight/plant, and weight of 1,000 kernels was obtained in monoculture (wheat/soybean).

Key words: crop succession, conventional tillage, minimum tillage, no-tillage, yield components.

\section{INTRODUÇÃO}

Os sistemas de manejos conservacionistas, ou seja, aqueles que demandam menor revolvimento de solo possível, aliado à manutenção da cobertura com palha, podem afetar positivamente as características químicas, físicas e biológicas do solo, interferindo por sua vez na distribuição das raízes, com reflexos no crescimento da parte aérea, interagindo conseqüientemente, no rendimento de grãos da espécie em cultivo (FRANZLUEBBERS, et al., 1994; KLEPKER

${ }^{1}$ Empresa Brasileira de Pesquisa Agropecuária (Embrapa trigo), Caixa Postal 451, CEP 99001-970 Passo Fundo, RS, Brasil. E-mail: hapsantos@cnpt.embrapa.br. Autor para correspondência.

${ }^{2}$ Embrapa Trigo. Passo Fundo, RS, Brasil. E-mail: julio@cnpt.embrapa.br.

${ }^{3}$ Embrapa Trigo. Passo Fundo, RS, Brasil. E-mail: spera@cnpt.embrapa.br. 
\&ANGHINONI, 1995; DAROS et al., 1997; FRANCHINI et al., 2000). Para que isso possa ser comprovado, tornase necessário conduzir experimentos por vários anos, envolvendo espécies tanto de inverno como de verão, em diferentes sistemas de rotação de culturas (HERNÁZ, et al., 1995; FONTANELI et al., 2000; SANTOS \& REIS, 2001). Nesse caso, as espécies podem ser avaliadas singularmente ou conjuntamente.

Tem sido observado que existem relativamente poucos trabalhos de longa duração avaliando rendimento de grãos de culturas sob sistemas de manejo de solo. Nos trabalhos encontrados até a metade da década de 90, não havia análise conjunta dos anos sobre rendimento de grãos de milho, soja, sorgo e trigo, sob diferentes sistemas de manejo de solo (SIDIRAS et al., 1983; EDWARDS et al., 1988; LANGDALE et al., 1990; RUEDELL, 1995). Porém, nos trabalhos publicados posteriormente, por SANTOS et al. (1995), por GHAFFARZADEH (1997), por YUSUF et al. (1999), por KLUTHCOUSKI et al. (2000) e por PAULETTI et al. (2003), não foi verificada diferença significativa entre os sistemas de manejo de solo para rendimento de grãos de aveia branca, cevada, milho e soja

Além disso, poucos são os trabalhos envolvendo análise conjunta de sistemas de manejo de solo e rotação de culturas na região Sul do Brasil. GAUDÊNCIO et al. (1986), EDWARDS et al. (1988), LANGDALE et al. (1990), RUEDELL (1995) e CIOTTA et al. (2002) estudaram sistemas de rotação de culturas, porém sem a análise conjunta dos anos para rendimento de grãos de soja. SANTOS et al. (1995), GHAFFARZADEH (1997) e YUSUF et al. (1999), comparando sistemas de rotação de culturas, no conjunto de anos, porém, não observaram diferença significativa para rendimento de grãos de soja.

Considerando somente sistemas de rotação de culturas envolvendo espécies de inverno ou de verão, SANTOS \& REIS (1991) em Passo Fundo, RS, observaram rendimentos de grãos mais elevados para a soja cultivada por dois ou três anos consecutivos, quando intercalada a milho. O menor rendimento de grãos dessa oleaginosa ocorreu sob monocultura. Em outros trabalhos, quando a soja foi cultivada sob plantio direto, os rendimentos de grãos foram mais elevados com um (trigo/soja e ervilhaca/milho) ou dois verões (trigo/soja, linho/soja e ervilhaca/milho) de rotação de culturas (SANTOS et al., 1997; 1998).

O sistema de manejo de solo mais usado sob o ponto de vista conservacionista é o plantio direto.

Para que o plantio direto se mantenha sustentável, é imprescidível que seja conduzido permanentemente sob sistema de rotação de culturas. Nesse caso, os resíduos vegetais na superfície do solo podem proporcionar tanto efeitos positivos como negativos sobre o crescimento de plantas de inverno ou de verão, estabelecidas em sucessão (ROMAN \& VELLOSO, 1993). No caso de soja cultivada sob determinados resíduos vegetais remanescentes de inverno (aveia branca, cevada e trigo), em Passo Fundo, RS e Guarapuava, PR, têm sido verificados rendimentos maiores do que sob outros resíduos, por exemplo: colza e linho (SANTOS \& ROMAN, 2001). Além disso, estatura de plantas, altura de inserção dos primeiros legumes e número de grãos por planta de soja, também podem ser afetadas positiva ou negativamente pelos resíduos vegetais (SANTOS \& REIS, 1991; SANTOS et al., 1997; 1998)

O presente trabalho teve por objetivo avaliar o efeito de sistemas de manejo de solo e de rotação culturas sobre algumas características agronômicas de soja.

\section{MATERIAL E MÉTODOS}

O experimento foi conduzido na Embrapa Trigo, no município de Passo Fundo, RS, no período de 1986 a 2002, em solo classificado como Latossolo Vermelho Distrófico típico (STRECK et al., 2002).

O delineamento experimental foi de blocos ao acaso, com parcelas subdivididas e três repetições. A parcela principal foi constituída pelos sistema de manejo de solo e as subparcelas pelos sistemas de rotação de culturas. A parcela principal media $360 \mathrm{~m}^{2}(4$ $\mathrm{m}$ de largura por $90 \mathrm{~m}$ de comprimento) e a subparcela $40 \mathrm{~m}^{2}$ ( $4 \mathrm{~m}$ de largura por $10 \mathrm{~m}$ de comprimento). Os tratamentos consistiram em quatro sistemas de manejo de solo - 1) plantio direto contínuo, 2) preparo de solo com implemento de cultivo mínimo "Jan", no inverno e semeadura direta, no verão, 3) preparo convencional de solo com arado de discos, no inverno e semeadura direta, no verão e 4) preparo convencional de solo com arado de aivecas, no inverno e semeadura direta, no verão - e em três sistemas de rotação de culturas: sistema I (trigo/soja), sistema II (trigo/soja e ervilhaca/milho ou sorgo) e sistema III (trigo/soja, ervilhaca/milho ou sorgo, e aveia branca/soja).

As cultivares de soja usadas foram BR-16, em 1997, BRS 137, em 1998 e 1999, e BRS 154, de 2000 a 2002, semeadas, preferencialmente, no mês de novembro (em época única).

A adubação de manutenção foi realizada de acordo com a indicação para as culturas de inverno e de verão, e baseada nos resultados da análise de solo (SOCIEDADE, 2004). As amostras de solo foram coletadas, anualmente, após a colheita das culturas de inverno.

Ciência Rural, v.36, n.1, jan-fev, 2006. 
A época de semeadura e o controle de plantas daninhas seguiram as indicações para as culturas de inverno e de verão. No presente trabalho, são apresentados os resultados de rendimento de grãos e dos componentes do rendimento de grãos de soja (número de legumes, número de grãos e peso de grãos por planta, população final, altura de inserção dos primeiros legumes, estatura de plantas), no período de 1997/98 a 2002/03. Foram avaliados os seguintes atributos: população final, altura de inserção dos primeiros legumes, estatura de plantas, rendimento de grãos (com umidade corrigida para 13\%), peso de 1.000 grãos e componentes do rendimento de soja (número de legumes, número de grãos e peso de grãos por planta).

Os valores de percentual de cobertura de solo provêm de cinco leituras de avaliação do resíduo cultural remanescente na superfície (HARTWING \& LAFLEN, 1978). A quantidade de palha na superfície do solo, foi avaliada por meio da coleta de $0,5 \mathrm{~m}^{2}$ de resíduo cultural remanescente.

Foi efetuada análise de variância, dentro de cada ano e na média conjunta dos anos, de 1997/98 a $2002 / 03$. Considerou-se o efeito do tratamento (diferentes sistemas de manejo de solo e sistemas de rotação de culturas) como fixo e o efeito do ano como aleatório. As médias foram comparadas entre si, pelo teste de Duncan, a 5\% de probabilidade, utilizando-se o pacote estatístico SAS versão 8.2 (STATISTICAL, 2003).

\section{RESULTADOS E DISCUSSÃO}

Para rendimento de grãos, foram notados efeitos de ano, sistemas de manejo de solo e rotação de culturas, além da interação tripla entre os três fatores (Tabelas 1, 2 e 3). O ano de 2000/01 foi superior aos demais anos estudados para rendimento de grão de soja. Para número de legumes e número de legumes por planta, houve somente efeito para o fator ano (Tabela 1). Para peso de grãos por planta, foram observados efeitos de ano, sistemas de rotação de culturas e interação ano versus sistemas de manejo de solo versus rotação de culturas (Tabelas 1,3 e 5). O maior número de legumes, número de grãos e peso de grãos por planta ocorreu na safra agrícola 2002/03. O peso de grãos mais elevado manifestou-se na soja cultivada após trigo, no sistema II e após aveia branca, no sistema III. Para peso de 1.000 grãos, foram verificados efeitos de ano, sistemas de manejo de solo, de rotação de culturas e interação ano versus sistemas de manejo de solo versus sistemas de rotação de culturas (Tabelas 1, 2, 4 e 5). O ano de 1999/00 foi superior aos demais anos estudados para peso de 1.000 grãos de soja. A soja cultivada no sistema plantio e no cultivo mínimo apresentaram maior peso de 1.000 grãos do que os sistemas convencionais de preparo de solo com arados de discos e com arado de aivecas. A monocultura de soja mostrou menor peso de 1.000 grãos, em relação a soja cultivada sob rotação de culturas. Para população final de plantas houve efeito de ano e sistemas de rotação de culturas (Tabelas 1 e 3). A população final de plantas de soja mais elevada manifestou-se na safra agrícola de 1997/98, em comparação com os demais períodos estudados. A soja cultivada após trigo, no sistema II, mostrou mais população final de plantas de soja do que os demais sistemas estudados. Para estatura de plantas, foram observados efeitos de ano, sistemas de manejo de solo, rotação de culturas e interação ano versus sistemas de manejo de solo versus sistemas de rotação de culturas (Tabelas 1, 2 e 4). A soja cultivada no período agrícola de 1998/99 apresentou maior estatura de plantas de soja do que os demais anos estudados. A soja cultivada sob plantio direto mostrou estatura de plantas superior aos demais sistema de manejo de solo. A soja cultivada após trigo, no sistema II e após aveia branca, sistema III, manifestou maior estatura de plantas demais elevada, em relação aos demais sistemas. Para altura de inserção dos primeiros legumes houve efeito de ano (Tabelas 1). A soja cultivada na safra agrícola de 1999/00 apresentou maior altura de inserção dos primeiros legumes, em comparação aos demais anos estudados. Isso indica que todas características foram afetadas por variações climáticas ocorridas entre os anos (Tabela 1). EDWARDS et al. (1988) e de PEDERSEN \& LAUER (2003), em rotação de culturas de trigo, soja e milho, em clima temperado e solos de elevada fertilidade e conteúdo de matéria orgânica encontraram resultados similares ao do presente estudo para rendimento de grãos, peso de 1.000 grãos e estatura de plantas de soja para sistemas de manejo de solo, para rotação de culturas e para a interação de sistemas de manejo de solo versus rotação de culturas.

Para três das seis safras estudadas, observaram-se diferenças significativas $(\mathrm{P}<0,05)$ no rendimento de grãos de soja, em virtude dos sistemas de manejo solo (Tabela 2). Em duas dessas três safras (1999/00 e 2000/01), o rendimento de grãos de soja cultivada sob plantio direto e sob cultivo mínimo foi superior ao da soja cultivada sob preparo convencional de solo com arado de discos e com arado de aivecas. Resultado semelhante foi obtido por SIDIRAS et al. (1983), em Londrina, PR, por EDWARDS et al. (1988) e por PEDERSEN \& LAUER (2003), nos Estados Unidos da América, principalmente em anos com escassez de precipitação pluvial. Nessas duas safras, o maior 
Tabela 1 - Significado do teste F quanto a oito características agronômicas de soja, semeada de 1997 a 2002. Passo Fundo, RS

\begin{tabular}{|c|c|c|c|c|c|c|c|}
\hline Características agronômicas & Ano & Manejo & Rotação & $\begin{array}{l}\text { Ano } \mathrm{x} \\
\text { manejo }\end{array}$ & $\begin{array}{c}\text { Ano x } \\
\text { rotação }\end{array}$ & $\begin{array}{l}\text { Manejo x } \\
\text { rotação }\end{array}$ & $\begin{array}{c}\text { Ano x manejo x } \\
\text { rotação }\end{array}$ \\
\hline Rendimento grãos $\left(\mathrm{kg} \mathrm{ha}^{-1}\right)$ & $*$ & $*$ & $*$ & $*$ & $*$ & $\mathrm{~ns}$ & $*$ \\
\hline Número de legumes por planta & $*$ & ns & ns & ns & ns & ns & $\mathrm{ns}$ \\
\hline Número de grãos por planta & $*$ & ns & ns & ns & ns & ns & ns \\
\hline Peso de grãos por planta (g) & $*$ & ns & $*$ & ns & $*$ & $*$ & $\mathrm{~ns}$ \\
\hline Peso de 1.000 grãos (g) & $*$ & $*$ & $*$ & ns & $*$ & $*$ & $\mathrm{~ns}$ \\
\hline População final de plantas $\left(\mathrm{m}^{2}\right)$ & $*$ & ns & $*$ & ns & $*$ & $\mathrm{~ns}$ & ns \\
\hline Estatura de plantas (cm) & $*$ & $*$ & $*$ & $*$ & $*$ & $\mathrm{~ns}$ & $*$ \\
\hline Altura inserção $1^{o s}$ legumes $(\mathrm{cm})$ & $*$ & $\mathrm{~ns}$ & ns & $\mathrm{ns}$ & ns & $\mathrm{ns}$ & ns \\
\hline
\end{tabular}

*: nível de significância de 5\%; e ns: não significativo.

Tabela 2- Efeito de sistema de manejo de solo no rendimento de grãos, no peso de 1.000 grãos e na estatura de plantas de soja, cultivar BR16, em 1997, BRS 137, de 1998 e 1999, e BRS 154, de 2000 a 2002. Passo Fundo, RS

\begin{tabular}{|c|c|c|c|c|c|}
\hline \multirow[b]{2}{*}{ Ano } & \multicolumn{4}{|c|}{ Manejo de solo } & \multirow[b]{2}{*}{ Média } \\
\hline & $\mathrm{PD}$ & PCD & PCA & $\mathrm{CM}$ & \\
\hline \multicolumn{6}{|c|}{ Rendimento de grãos $\left(\mathrm{kg} \mathrm{ha}^{-1}\right)$} \\
\hline $1997 / 98$ & $2.803 \mathrm{Ac}$ & $2.770 \mathrm{Ab}$ & $2.746 \mathrm{Aab}$ & $2.731 \mathrm{Ac}$ & $2.762 \mathrm{c}$ \\
\hline 1998/99 & $2.126 \mathrm{Ae}$ & $2.196 \mathrm{Ac}$ & $2.223 \mathrm{Ac}$ & $2.272 \mathrm{Ad}$ & $2.204 \mathrm{e}$ \\
\hline 1999/00 & $3.106 \mathrm{Ab}$ & $2.853 \mathrm{Bb}$ & $2.748 \mathrm{Cab}$ & $3.132 \mathrm{Ab}$ & $2.960 \mathrm{~b}$ \\
\hline $2000 / 01$ & $3.536 \mathrm{Aa}$ & $3.250 \mathrm{Ba}$ & $2.948 \mathrm{Ca}$ & $3.560 \mathrm{Aa}$ & $3.324 \mathrm{a}$ \\
\hline $2001 / 02$ & $2.591 \mathrm{Ad}$ & $2.408 \mathrm{Bc}$ & $2.540 \mathrm{ABb}$ & $2.773 \mathrm{Ac}$ & $2.578 \mathrm{~d}$ \\
\hline $2002 / 03$ & $2.952 \mathrm{Ab}$ & $2.698 \mathrm{Ab}$ & $2.788 \mathrm{Aa}$ & $2.887 \mathrm{Ab}$ & $2.831 \mathrm{bc}$ \\
\hline Média & $2.852 \mathrm{~A}$ & $2.696 \mathrm{~B}$ & $2.666 \mathrm{~B}$ & $2.893 \mathrm{~A}$ & 2.777 \\
\hline \multicolumn{6}{|c|}{ Peso de 1.000 grãos $(\mathrm{g})$} \\
\hline $1997 / 98$ & $172,42 \mathrm{Ab}$ & $171,33 \mathrm{Ab}$ & $170,78 \mathrm{Ab}$ & $174,70 \mathrm{Ab}$ & $172,31 \mathrm{c}$ \\
\hline 1998/99 & $155,39 \mathrm{Ac}$ & $156,00 \mathrm{Ac}$ & $156,26 \mathrm{Ac}$ & $158,51 \mathrm{Ac}$ & $156,54 \mathrm{~d}$ \\
\hline 1999/00 & $195,65 \mathrm{Aa}$ & $186,72 \mathrm{Ba}$ & $185,34 \mathrm{Ba}$ & $196,22 \mathrm{Aa}$ & $190,98 \mathrm{a}$ \\
\hline $2000 / 01$ & $192,02 \mathrm{Aa}$ & $183,68 \mathrm{Ba}$ & $179,51 \mathrm{Ba}$ & $193,29 \mathrm{Aa}$ & $187,12 b$ \\
\hline $2001 / 02$ & $178,77 \mathrm{Ab}$ & $165,66 \mathrm{Cb}$ & $170,41 \mathrm{Bb}$ & $177,95 \mathrm{Ab}$ & $173,20 \mathrm{c}$ \\
\hline $2002 / 03$ & $188,27 \mathrm{Aa}$ & $179,84 \mathrm{Ba}$ & $179,85 \mathrm{Ba}$ & $190,13 \mathrm{Aa}$ & $184,52 \mathrm{~b}$ \\
\hline Média & $180,42 \mathrm{~A}$ & $173,87 \mathrm{~B}$ & $173,69 \mathrm{~B}$ & $181,80 \mathrm{~A}$ & 177,45 \\
\hline \multicolumn{6}{|c|}{ Estatura de plantas $(\mathrm{cm})$} \\
\hline $1997 / 98$ & $96 \mathrm{Ab}$ & $95 \mathrm{Ab}$ & $93 \mathrm{Ab}$ & $95 \mathrm{Ab}$ & $95 \mathrm{~b}$ \\
\hline 1998/99 & $105 \mathrm{Aa}$ & $101 \mathrm{Aa}$ & $103 \mathrm{Aa}$ & 104 Аa & $103 \mathrm{a}$ \\
\hline $1999 / 00$ & $89 \mathrm{Ac}$ & $83 \mathrm{Bc}$ & $82 \mathrm{Bd}$ & $88 \mathrm{Ac}$ & $85 \mathrm{~d}$ \\
\hline $2000 / 01$ & $83 \mathrm{Ad}$ & $79 \mathrm{Ad}$ & $77 \mathrm{Ae}$ & $81 \mathrm{Ad}$ & $80 \mathrm{f}$ \\
\hline $2001 / 02$ & $95 \mathrm{Ab}$ & $86 \mathrm{Bc}$ & $88 \mathrm{Bc}$ & $93 \mathrm{Ab}$ & $91 \mathrm{c}$ \\
\hline $2002 / 03$ & $91 \mathrm{Ac}$ & $78 \mathrm{Ce}$ & $79 \mathrm{Cd}$ & $85 \mathrm{Bc}$ & $83 \mathrm{e}$ \\
\hline Média & $93 \mathrm{~A}$ & $87 \mathrm{C}$ & $87 \mathrm{C}$ & $91 \mathrm{~B}$ & 89 \\
\hline
\end{tabular}

$\mathrm{CV}$ : rendimento de grãos $-6 \%$; peso de 1.000 grãos - 3\%; e estatura de plantas - $5 \%$.

PD: plantio direto

PCD: preparo convencional de solo com arado de discos, no inverno e semeadura direta, no verão.

PCA: preparo convencional de solo com arado de aivecas, no inverno e semeadura direta, no verão.

CM: cultivo mínimo

Médias seguidas da mesma letra, minúscula na vertical e maiúscula na horizontal, não apresentam diferenças significativas, a $5 \%$ de probabilidade, pelo teste de Duncan.

Ciência Rural, v.36, n.1, jan-fev, 2006. 
Tabela 3 - Efeito de rotação de culturas no rendimento de grãos, na população final de plantas e no peso de grãos de plantas de soja, cultivar BR-16, em 1997, BRS 137, de 1998 e 1999, e BRS 154, de 2000 a 2002. Passo Fundo, RS

\begin{tabular}{|c|c|c|c|c|c|}
\hline \multirow[b]{2}{*}{ Ano } & \multicolumn{4}{|c|}{ Sistema de rotação } & \multirow[b]{2}{*}{ Média } \\
\hline & Sistema I: soja/trigo & $\begin{array}{l}\text { Sistema II: soja/trigo e } \\
\text { milho/ervilhaca }\end{array}$ & $\begin{array}{l}\text { Sistema III: soja/ aveia } \\
\text { branca, soja/ trigo e } \\
\text { milho/ ervilhaca }\end{array}$ & $\begin{array}{c}\text { Sistema III: soja/ trigo, } \\
\text { milho/ ervilhaca e soja } \\
\text { aveia branca }\end{array}$ & \\
\hline & \multicolumn{5}{|c|}{ Rendimento de grãos $\left(\mathrm{kg} \mathrm{ha}^{-1}\right)$} \\
\hline $1997 / 98$ & $2.636 \mathrm{Cc}$ & $2.932 \mathrm{Ac}$ & $2.789 \mathrm{Bc}$ & $2.692 \mathrm{Bc}$ & $2.762 \mathrm{c}$ \\
\hline $1998 / 99$ & $2.153 \mathrm{Ae}$ & $2.269 \mathrm{Ae}$ & $2.187 \mathrm{Ae}$ & $2.208 \mathrm{Ad}$ & $2.204 \mathrm{e}$ \\
\hline $1999 / 00$ & $2.703 \mathrm{Cc}$ & $3.167 \mathrm{Ab}$ & $3.098 \mathrm{Ab}$ & $2.870 \mathrm{Bb}$ & $2.960 \mathrm{~b}$ \\
\hline $2000 / 01$ & $3.036 \mathrm{Ba}$ & $3.421 \mathrm{Aa}$ & $3.422 \mathrm{Aa}$ & $3.416 \mathrm{Aa}$ & $3.324 \mathrm{a}$ \\
\hline $2001 / 02$ & $2.427 \mathrm{Bd}$ & $2.720 \mathrm{Ad}$ & $2.466 \mathrm{Bd}$ & $2.699 \mathrm{Ac}$ & $2.578 \mathrm{~d}$ \\
\hline $2002 / 03$ & $2.865 \mathrm{Ab}$ & $2.689 \mathrm{Bd}$ & $2.830 \mathrm{Ac}$ & $2.941 \mathrm{Ab}$ & $2.831 \mathrm{bc}$ \\
\hline \multirow[t]{2}{*}{ Média } & $2.636 \mathrm{C}$ & $2.866 \mathrm{~A}$ & $2.799 \mathrm{~B}$ & $2.804 \mathrm{~B}$ & 2.777 \\
\hline & \multicolumn{5}{|c|}{ População final de plantas $/ \mathrm{m}^{2}$} \\
\hline $1997 / 98$ & $39 \mathrm{Aa}$ & $39 \mathrm{Aa}$ & $36 \mathrm{Aa}$ & $37 \mathrm{Aa}$ & $38 \mathrm{a}$ \\
\hline $1999 / 00$ & $25 \mathrm{Bc}$ & $31 \mathrm{Ab}$ & $32 \mathrm{Ab}$ & $30 \mathrm{Ab}$ & $29 \mathrm{~b}$ \\
\hline $2000 / 01$ & $21 \mathrm{Ad}$ & $23 \mathrm{Ac}$ & $23 \mathrm{Ad}$ & $22 \mathrm{Ac}$ & $22 \mathrm{c}$ \\
\hline $2001 / 02$ & $28 \mathrm{Ab}$ & $29 \mathrm{Ab}$ & $28 \mathrm{Ac}$ & $28 \mathrm{Ab}$ & $28 \mathrm{~b}$ \\
\hline $2002 / 03$ & $29 \mathrm{Ab}$ & $30 \mathrm{Ab}$ & $27 \mathrm{Ac}$ & $29 \mathrm{Ab}$ & $29 \mathrm{~b}$ \\
\hline \multirow[t]{2}{*}{ Média } & $28 \mathrm{~B}$ & $30 \mathrm{~A}$ & $29 \mathrm{~A}$ & $29 \mathrm{AB}$ & 29 \\
\hline & \multicolumn{5}{|c|}{ Peso de grãos por planta $(\mathrm{g})$} \\
\hline $1997 / 98$ & $8,06 \mathrm{Bc}$ & $9,90 \mathrm{Ac}$ & $8,74 \mathrm{Abc}$ & $9,01 \mathrm{Ac}$ & $8,93 \mathrm{~cd}$ \\
\hline $1999 / 99$ & $7,40 \mathrm{Ad}$ & $8,38 \mathrm{Ad}$ & $8,11 \mathrm{Ac}$ & $8,33 \mathrm{Ad}$ & $8,05 \mathrm{~d}$ \\
\hline $1999 / 00$ & 7,69 Acd & 9,17 Ac & $8,06 \mathrm{Ac}$ & $8,41 \mathrm{Ad}$ & $8,33 \mathrm{~d}$ \\
\hline $2000 / 01$ & $10,42 \mathrm{Bb}$ & $12,24 \mathrm{Ab}$ & $13,12 \mathrm{Ab}$ & $13,46 \mathrm{Ab}$ & $12,31 \mathrm{~b}$ \\
\hline $2001 / 02$ & $9,08 \mathrm{Ab}$ & $10,01 \mathrm{Ac}$ & $9,38 \mathrm{Ac}$ & $10,32 \mathrm{Ac}$ & $9,70 \mathrm{c}$ \\
\hline $2002 / 03$ & $18,78 \mathrm{Aa}$ & $16,44 \mathrm{Ba}$ & $17,95 \mathrm{Aa}$ & $17,79 \mathrm{Aa}$ & $17,74 \mathrm{a}$ \\
\hline Média & $10,24 \mathrm{~B}$ & $11,02 \mathrm{~A}$ & $10,89 \mathrm{~A}$ & $11,22 \mathrm{~A}$ & 10,84 \\
\hline
\end{tabular}

C.V.: rendimento de grãos $-6 \%$; população final de plantas $-12 \%$; e peso de grãos por planta - $16 \%$.

Sistema I: trigo/soja.

Sistema II: trigo/soja e ervilhaca/milho ou sorgo, em 2001.

Sistema III: trigo/soja, ervilhaca/milho ou sorgo, em 2001 e aveia branca/soja.

A: aveia branca, S: soja e T: trigo.

Médias seguidas da mesma letra, minúscula na vertical e maiúscula na horizontal, não apresentam diferenças significativas, a $5 \%$ de probabilidade, pelo teste de Duncan.

rendimento de grãos de soja nos sistemas conservacionistas de solo pode ser explicado, em parte, pelo peso de 1.000 grãos, que foi mais elevado em relação aos sistemas de preparo convencional de solo (Tabela 2). O peso de 1.000 grãos mais elevado, nos sistemas conservacionistas pode ser explicado, em parte, pela maior disponibilidade de água e acúmulo de nutrientes e de matéria orgânica na camada superficial, em comparação aos métodos de preparo convencional de solo (DERPSCH et al., 1991; SANTOS \& TOMM, 2003). Nessas duas safras, o menor rendimento de grãos ocorreu na soja cultivada sob preparo convencional de solo com arado de aivecas. Na terceira safra (2001/ 02), a soja cultivada sob cultivo mínimo e sob plantio direto apresentou rendimento de grãos mais elevado, em relação ao preparo convencional de solo com arado de discos.

Na análise conjunta das safras (1997/98 a 2002/03), a soja cultivada sob plantio direto e sob cultivo mínimo apresentou rendimento de grãos superior ao da soja cultivada sob preparo convencional de solo com arado de discos e com arado de aivecas (Tabela 2). Parte da explicação atribuível a essa diferença entre os sistemas de manejo de solo pode estar relacionada a estatura de plantas que, no plantio direto, foi maior do que os demais sistemas de manejo de solo (Tabela 2). De acordo com DERPSCH et al. (1991), a cobertura de solo através de resíduos vegetais oriundos de rotação de culturas, nos sistemas conservacionistas mantém a água disponível, mesmo em período de estiagem, desde que tenha chovido anteriormente, 
Tabela 4 - Efeito de rotação de culturas no peso de 1.000 de grãos e na estatura de plantas de soja, cultivar BR-16, em 1997, BRS 137, de 1998 e 1999, e BRS 154, de 2000 a 2002. Passo Fundo, RS

\begin{tabular}{|c|c|c|c|c|c|}
\hline \multirow[b]{2}{*}{ Ano } & \multicolumn{4}{|c|}{ Sistema de rotação } & \multirow[b]{2}{*}{ Média } \\
\hline & Sistema I: soja/trigo & $\begin{array}{l}\text { Sistema II: soja/trigo } \\
\text { e milho/ervilhaca }\end{array}$ & $\begin{array}{l}\text { Sistema III: soja/ aveia } \\
\text { branca, trigo/soja e } \\
\text { milho/ervilhaca }\end{array}$ & $\begin{array}{c}\text { Sistema III: soja/ trigo, } \\
\text { milho/ ervilhaca e soja/ } \\
\text { aveia branca }\end{array}$ & \\
\hline \multicolumn{6}{|c|}{ Peso de 1.000 grãos $(\mathrm{g})$} \\
\hline $1997 / 98$ & $167,90 \mathrm{Bd}$ & $174,78 \mathrm{Ad}$ & $173,65 \mathrm{Ac}$ & $172,92 \mathrm{Ab}$ & $172,31 \mathrm{c}$ \\
\hline $1998 / 99$ & $156,22 \mathrm{ABe}$ & $159,55 \mathrm{Ae}$ & $157,13 \mathrm{Ad}$ & $153,26 \mathrm{Bc}$ & $156,54 \mathrm{~d}$ \\
\hline $1999 / 00$ & $184,02 \mathrm{Ba}$ & $195,91 \mathrm{Aa}$ & $192,52 \mathrm{Aa}$ & 191,49 Аа & $190,98 \mathrm{a}$ \\
\hline $2000 / 01$ & $179,01 \mathrm{Bb}$ & $190,12 \mathrm{Ab}$ & $190,69 \mathrm{Aa}$ & $188,68 \mathrm{Aa}$ & $187,12 b$ \\
\hline $2001 / 02$ & $173,80 \mathrm{Ac}$ & $173,32 \mathrm{Ad}$ & $171,51 \mathrm{Ac}$ & $174,16 \mathrm{Ab}$ & $173,20 \mathrm{c}$ \\
\hline $2002 / 03$ & $184,08 \mathrm{ABa}$ & $181,99 \mathrm{Bc}$ & $184,99 \mathrm{Ab}$ & $187,04 \mathrm{Aa}$ & $184,52 \mathrm{~b}$ \\
\hline Média & $174,17 \mathrm{~B}$ & $179,28 \mathrm{~A}$ & $178,41 \mathrm{~A}$ & $177,92 \mathrm{~A}$ & 177,45 \\
\hline \multicolumn{6}{|c|}{ Estatura de plantas $(\mathrm{cm})$} \\
\hline $1997 / 98$ & $95 \mathrm{Ab}$ & $94 \mathrm{Ac}$ & $97 \mathrm{Ab}$ & $94 \mathrm{Ab}$ & $95 \mathrm{~b}$ \\
\hline $1998 / 99$ & $103 \mathrm{Aa}$ & $106 \mathrm{Aa}$ & $102 \mathrm{Ba}$ & $103 \mathrm{Aa}$ & $103 \mathrm{a}$ \\
\hline $1999 / 00$ & $80 \mathrm{Cd}$ & $88 \mathrm{Ad}$ & $85 \mathrm{Bd}$ & $88 \mathrm{Ac}$ & $85 \mathrm{~d}$ \\
\hline $2000 / 01$ & $73 \mathrm{Be}$ & $82 \mathrm{Ae}$ & $82 \mathrm{Ae}$ & $83 \mathrm{Ad}$ & $80 \mathrm{f}$ \\
\hline $2001 / 02$ & $88 \mathrm{Cc}$ & $97 \mathrm{Ab}$ & $92 \mathrm{Bc}$ & $85 \mathrm{Cc}$ & $91 \mathrm{c}$ \\
\hline $2002 / 03$ & $85 \mathrm{Ac}$ & $82 \mathrm{Be}$ & $86 \mathrm{Ad}$ & $79 \mathrm{Ce}$ & $83 \mathrm{e}$ \\
\hline Média & $87 \mathrm{~B}$ & $91 \mathrm{~A}$ & $91 \mathrm{~A}$ & $88 \mathrm{~B}$ & 89 \\
\hline
\end{tabular}

CV: peso de 1.000 grãos - $3 \%$; e estatura de plantas - $5 \%$.

Sistema I: trigo/soja.

Sistema II: trigo/soja e ervilhaca/milho ou sorgo, em 2001.

Sistema III: trigo/soja, ervilhaca/milho ou sorgo, em 2001 e aveia branca/soja.

A: aveia branca, S: soja e T: trigo.

Médias seguidas da mesma letra, minúscula na vertical e maiúscula na horizontal, não apresentam diferenças significativas, a 5 \% de probabilidade, pelo teste de Duncan.

permitindo que as plantas cresça mais do que nos preparos convencionais do solo. Além disso, pode haver acúmulo de nutrientes e de matéria orgânica na camada superficial do solo (SANTOS \& TOMM, 2003). Na primeira avaliação deste trabalho, de 1987/88 a 1996/ 97, não foi possível esclarecer a diferença entre os sistemas conservacionistas e os sistemas de preparo convencional de solo, ou seja, a soja cultivada sob cultivo mínimo e sob preparo convencional com arado discos apresentou rendimento de grãos mais elevado do a soja cultivada sob preparo convencional com arado de aivecas (SANTOS et al., 2001).

CIOTTA et al. (2002), estudando sistemas de manejo de solo, em Latossolo Bruno de Guarapuava, PR, no período de 1978 a 2000, avaliaram 39 safras, das quais 18 foram de soja, quatro de milho, sete de trigo, sete de cevada e três de aveia branca. O rendimento de soja foi $42 \%$ maior sob plantio direto do que em preparo convencional de solo com arado de discos. PEDERSEN \& LAUER (2003), em Chernossolo Argilúvico Órtico, nos Estados Unidos, avaliando sistemas de manejo de solo, também encontraram maior rendimento de grãos
(6 a 8\%), estatura de plantas (6\%) e peso de 1.000 grãos de soja (2\%) em plantio direto, quando comparado com preparo convencional de solo.

Deve ser levado em conta que, na quantificação da palha, nesse experimento, de 1997 a 2002, encontrou-se diferença significativa entre os métodos de preparo de solo e de rotação de culturas. A quantidade média de palha sobre o solo, avaliada no fim do inverno de cada ano no plantio direto foi de $5,36 \mathrm{Mg} \mathrm{ha}^{-1}$, valor bem superior em comparação aos demais sistemas de manejo de solo que foram: $3,06 \mathrm{Mg}$ ha $^{-1}$ no cultivo mínimo, $0,44 \mathrm{Mg} \mathrm{ha}^{-1}$ no preparo convencional de solo com arado de discos e $0,49 \mathrm{Mg}$ ha $^{-1}$ no preparo com arado de aivecas. Desse modo, o plantio direto apresentou cobertura de solo de $93 \%$, enquanto o cultivo mínimo $45 \%$, o convencional de solo com arados de discos $2 \%$ e com arado de aivecas $3 \%$. A quantidade de palha remanescente sobre o solo é fundamental para o armazenamento de água, de nutrientes e de matéria orgânica no solo. Nos métodos de preparo conservacionista do solo, a capacidade de armazenamento de água geralmente é maior porque o 
Tabela 5 - Efeito de sistemas de manejo de solo e de rotação de culturas no peso de grãos e no peso de 1000 grãos de soja, cultivar BR-16, em 1997, BRS 137, de 1998 e 1999, e BRS 154, de 2000 a 2002. Passo Fundo, RS

\begin{tabular}{|c|c|c|c|c|c|}
\hline \multirow[b]{2}{*}{$\begin{array}{l}\text { Sistema } \\
\text { manejo }\end{array}$} & \multicolumn{4}{|c|}{ Sistema de rotação } & \multirow[b]{2}{*}{ Média } \\
\hline & $\begin{array}{l}\text { Sistema I: } \\
\text { soja/trigo }\end{array}$ & $\begin{array}{l}\text { Sistema II: soja/ } \\
\text { trigo }\end{array}$ & $\begin{array}{c}\text { Sistema III: soja/ aveia } \\
\text { branca, trigo/soja e milho/ } \\
\text { ervilhaca }\end{array}$ & $\begin{array}{c}\text { Sistema III: soja/trigo, } \\
\text { milho/ ervilhaca e aveia } \\
\text { branca/soja }\end{array}$ & \\
\hline & \multicolumn{5}{|c|}{ Peso de grãos por planta (g) } \\
\hline PD & $9,93 \mathrm{Ba}$ & $11,88 \mathrm{Aa}$ & $10,74 \mathrm{Ab}$ & $11,32 \mathrm{Aa}$ & $10,97 \mathrm{a}$ \\
\hline PCD & $10,77 \mathrm{Aa}$ & $10,66 \mathrm{Ab}$ & $10,43 \mathrm{Ab}$ & $10,26 \mathrm{Ab}$ & $10,53 \mathrm{a}$ \\
\hline PCA & 9,86 Аa & $10,55 \mathrm{Ab}$ & $10,51 \mathrm{Ab}$ & $11,01 \mathrm{Ab}$ & $10,48 \mathrm{a}$ \\
\hline $\mathrm{CM}$ & $10,38 \mathrm{Ca}$ & $10,99 \mathrm{Ba}$ & $11,90 \mathrm{Aa}$ & $12,29 \mathrm{Aa}$ & $11,39 \mathrm{a}$ \\
\hline Média & $10,24 \mathrm{~B}$ & $11,02 \mathrm{~A}$ & $10,89 \mathrm{~A}$ & $11,22 \mathrm{~A}$ & 10,84 \\
\hline \multicolumn{6}{|c|}{ Peso de 1.000 grãos (g) } \\
\hline PD & $173,81 \mathrm{Ba}$ & $182,62 \mathrm{Aa}$ & $182,08 \mathrm{Aa}$ & $183,17 \mathrm{Aa}$ & $180,42 \mathrm{a}$ \\
\hline PCD & $172,30 \mathrm{Bb}$ & $177,15 \mathrm{Ab}$ & $174,19 \mathrm{Ab}$ & $171,86 \mathrm{Bb}$ & $173,87 \mathrm{~b}$ \\
\hline PCA & $173,28 \mathrm{Aab}$ & $176,00 \mathrm{Ab}$ & $173,72 \mathrm{Ab}$ & $171,76 \mathrm{Ab}$ & $173,69 \mathrm{~b}$ \\
\hline $\mathrm{CM}$ & $177,29 \mathrm{Ba}$ & $181,33 \mathrm{Aa}$ & $183,67 \mathrm{Aa}$ & $184,90 \mathrm{Aa}$ & $181,80 \mathrm{a}$ \\
\hline Média & $174,17 \mathrm{~B}$ & $179,28 \mathrm{~A}$ & $178,41 \mathrm{~A}$ & $177,92 \mathrm{~A}$ & 177,45 \\
\hline
\end{tabular}

$\mathrm{CV}$ : rendimento de grãos $-6 \%$; e estatura de plantas $-5 \%$.

PD: plantio direto.

PCD: preparo convencional de solo com arado de discos, no inverno e semeadura direta, no verão.

PCA: preparo convencional de solo com arado de aivecas, no inverno e semeadura direta, no verão.

CM: cultivo mínimo.

Sistema I: trigo/soja.

Sistema II: trigo/soja e ervilhaca/milho ou sorgo, em 2001.

Sistema III: trigo/soja, ervilhaca/milho ou sorgo, em 2001 e aveia branca/soja.

A: aveia branca, S: soja e T: trigo.

Médias seguidas da mesma letra, minúscula na vertical e maiúscula na horizontal, não apresentam diferenças significativas, a $5 \%$ de probabilidade, pelo teste de Duncan.

solo sob plantio direto é mais estruturado e sofre menor perda de água por evaporação (DERPSCH et al., 1991).

Na comparação entre as safras de 1997/1998 a 2002/03, houve diferenças significativas no rendimento anual de grãos de soja, em função da rotação de culturas (Tabela 3). Em quatro das seis safras estudadas, o rendimento de grãos de soja cultivada sob rotação de culturas (sistemas II: trigo/soja e ervilhaca/milho ou sorgo e III: trigo/soja, ervilhaca/ milho ou sorgo e aveia branca/soja) foi mais elevado do que em soja cultivada sob monocultura (sistema I: trigo/soja). Resultados similares foram obtidos por SANTOS \& REIS (1991), em Passo Fundo, RS e por RUEDELL (1995), na região de Cruz Alta, RS. No trabalho, de Passo Fundo, RS, foram efetuados três cultivos de soja após trigo e um após aveia branca. SANTOS et al. (1997; 1998) observaram que o efeito da rotação de culturas sobre o rendimento de grãos de soja foi maior do que o do resíduo vegetal remanescente de inverno. Nesse período de estudo, a rotação de culturas foi de suma importância para a rendimento de soja (SANTOS \& REIS, 1991).
$\mathrm{Na}$ análise conjunta, envolvendo a média geral das safras de 1997/98 a 2002/03, encontraram-se diferenças significativas para rendimento de grãos de soja dentre os sistemas de rotação de culturas (Tabela 3). O rendimento de grãos de soja cultivada em rotação de um verão foi superior aos demais sistemas estudados (sistemas I e III). A explicação dessa diferença, pode estar relacionada, em parte, à população final de plantas, ao peso de grãos por planta, ao peso de 1.000 grãos e à estatura de plantas de soja (Tabelas 3 e 4) que nos sistemas sob rotação de culturas foram maiores do que em monocultura dessa oleaginosa. Trabalhos mais antigos revelaram que, quando a monocultura de qualquer espécies era praticada durante anos seguidos, evidenciava-se a liberação de alguns compostos durante a decomposição dos resíduos vegetais, que se acumulavam no solo até atingirem concentrações inibidoras do crescimento da própria planta. SANTOS et al. (1998) observaram, igualmente, que a soja cultivada sob rotação de culturas apresentou peso de 1.000 grãos mais elevado do que sob monocultura. No período de 1997/98 a 2002/03, a soja cultivada sob 
monocultura apresentou o menor rendimento de grãos. Resultado semelhante, em parte, foi obtido por LANGDALE et al. (1990), nos Estados Unidos. A soja cultivada após sorgo apresentou maior rendimento de grãos do que a soja cultivada em monocultura, durante dois ciclos de quatro anos de rotação. Também, nos Estados Unidos, PEDERSEN \& LAUER (2003), num período de quatro anos, observaram que soja em rotação com milho produziu $8 \%$ a mais do que em monocultura. Os mesmos autores, obtiveram maior peso de 1.000 grãos e estatura de plantas de soja quando em rotação de culturas em relação à monocultura. Deve ser levado em consideração que, no presente trabalho, a soja foi cultivada após aveia branca e após trigo por dois anos consecutivos (soja após aveia branca e soja após trigo). Esses resultados referidos anteriormente são similares a resultados obtidos por SANTOS et al. (2001), nesse mesmo experimento, em avaliação de 1987/ 88 a 1996/97.

Para alguns trabalhos elaborados a partir de ensaios conduzidos sob distintos sistemas de manejo de solo e sob rotação de culturas, não foi efetuada avaliação da média geral dos resultados para rendimento de grãos de soja (GAUDÊNCIO et al., 1986; EDWARDS et al., 1988; LANGDALE et al., 1990; RUEDELL, 1995). Para outros trabalhos, nos quais foram avaliadas rotações de culturas, não foram encontradas diferenças significativas entre as médias do rendimento de grãos de soja (SANTOS et al., 1995; GHAFFARZADEH, 1997; YUSUF et al., 1999). Todavia, PEDERSEN \& LAUER (2003) encontraram diferenças tanto para sistemas de manejo de solo como para rotações de culturas.

Por outro lado, para rendimento de grãos de soja sob rotação de culturas foi observada diferença significativa entre os sistemas estudados. Em trabalho conduzido em Passo Fundo, RS, em Latossolo Vermelho Distrófico, durante nove safras com soja cultivada por duas safras (trigo/soja, aveia branca/soja e ervilhaca/milho) ou três safras consecutivos (trigo/ soja, colza/soja, cevada/soja e serradela/milho ou trigo/ soja, colza/soja, linho/soja e serradela/milho), com preparo convencional de solo, no inverno e semeadura direta, no verão, o rendimento de grãos foi mais elevado após aveia branca, cevada e trigo, quando comparado com soja cultivada após colza ou em monocultura (SANTOS \& REIS, 1991). Nos trabalhos desenvolvidos por SANTOS et al. (1997; 1998), em Guarapuava, PR, em Latossolo Bruno Alumínico, durante dez safras, sob plantio direto, o rendimento de grãos de soja cultivada por dois anos (cevada/soja, aveia branca/soja e ervilhaca/milho ou trigo/soja, linho/soja e ervilhaca/ milho) ou três anos consecutivos (cevada/soja, linho/ soja, aveia/soja e ervilhaca/milho ou trigo/soja, aveia/ soja, cevada/soja e ervilhaca/milho) foi mais elevado após cevada, aveia branca e trigo, em relação ao de soja cultivada após linho. Nesses casos, o menor rendimento de grãos de soja esteve relacionado com o resíduo vegetal remanescente de linho (SANTOS \& ROMAN, 2001) e não com o sistema de rotação de culturas.

O resultado da interação ano versus sistemas de manejo de solo versus rotação de culturas afetou a soja cultivada sob plantio direto e sob cultivo mínimo, e, como consequiência, a cultura de soja apresentou maior peso de 1.000 grãos quando sob rotação de culturas por um verão com milho ou sorgo, em relação à monocultura (Tabela 5). Isso, por sua vez, repercutiu no rendimento de grãos de soja, nesses sistemas de manejo de solo e de rotação de culturas (Tabelas 2 e 3). Menor rendimento de grãos ocorreu em soja cultivada sob preparo convencional de solo com arado de discos e com arado de aivecas. Isso demonstra, em parte, que o efeito da rotação de culturas foi de suma importância para manutenção dos sistemas conservacionistas de manejo de solo, dentre eles o plantio direto.

\section{CONCLUSÕES}

Na média das safras e independente de rotação, a soja cultivada sob plantio direto e sob cultivo mínimo apresenta maior rendimento de grãos, maior peso de 1.000 grãos e maior estatura de plantas, que a soja cultivada sob preparo convencional de solo com arado de discos ou com arado de aivecas.

A rotação de culturas com um verão (milho ou sorgo) propicia maior rendimento de grãos de soja, em comparação com os demais sistemas estudados. $\mathrm{O}$ menor rendimentos de grãos de soja ocorreu em monocultura.

O menor peso de grãos e peso de 1000 grãos ocorreu quando em monocultura (trigo/soja).

A combinação de sistemas conservacionistas de manejo de solo e rotação de culturas favorece maior rendimento da cultura de soja.

\section{AGRADECIMENTOS}

Ao Conselho Nacional de Desenvolvimento Científico e Tecnológico (CNPq), pela bolsa de Produtividade em Pesquisa concedida à Santos.

\section{REFERÊNCIAS}

CIOTTA, M.N. et al. Acidificação de Latossolo sob plantio direto. Revista Brasileira de Ciência do Solo, Viçosa, v.26, n.4, p.1055-1064, 2002.

DA ROS, C.O. et al. Manejo do solo a partir de campo nativo: efeito sobre a forma e estabilidade da estrutura ao final de cinco

Ciência Rural, v.36, n.1, jan-fev, 2006. 
anos. Revista Brasileira de Ciência de Solo, Campinas, v.21, n.2, p.241-247, 1997.

DERPSCH, R. et al. Importância da rotação de culturas. In Controle da erosão no Paraná, Brasil: sistemas de cobertura do solo, plantio direto e preparo conservacionista do solo. Eschborn: GTZ/IAPAR, 1991. p.147-164.

EDWARDS, J.H. et al. Influence of tillage and crop rotation on yields of corn, soybean, and wheat. Agronomy Journal, Madison, v.80, n.1, p.76-80, 1988.

FONTANELI, R.S. et al. Análise econômica de sistemas de produção de grãos com pastagens de inverno, em sistema plantio direto. Pesquisa Agropecuária Brasileira, Brasília, v.35 n.11, p.2129-2137, 2000

FRANCHINI, J.C. et al. Alterações na fertilidade do solo em sistemas de rotação de culturas em semeadura direta. Revista Brasileira de Ciência do Solo, Viçosa, v.24, n.2, p.459467, 2000.

FRANZLUEBBERS, A.J. et al. Long-term chances in soil carbon and nitrogen pools in wheat management systems, Soil Science Society of America Journal, Madison, v.58, n.6, p.1639-1645, 1994.

GAUDÊNCIO, C.A. et al. Rotação de culturas com a soja no norte do Estado do Paraná. Londrina: EMBRAPACNPSo, 1986. 10p. (EMBRAPA-CNPSo. Pesquisa em Andamento, 10).

GHAFFARZADEH, M. Economic and biological benefits of intercropping berseem clover with oat in corn-soybean-oa rotations. Journal of Production Agriculture, Madison, v.10, n.2, p.314-319, 1997.

HARTWING, R.O.; LAFLEN, J.M. A meterstick method for measuring crop residue cover. Journal of Soil and Water Conservation, Ankeny, v.33, n.2, p.90-91, 1978.

HERNÁZ, J.L. et al. Long-term energy use and economic evaluation of three tillage systems for cereal and legume production in central Spain. Soil \& Tillage Research, Amsterdam, v. 35, n. 4, p.183-198, 1995.

KLEPKER, D.; ANGHINONI, I. Caracteríticas físicas e químicas do solo afetadas por métodos de preparo e modos de adubação. Revista Brasileira de Ciência de Solo, Campinas, v.19, n.3, p.395-401, 1995.

KLUTHCOUSKI, J. et al. Manejo do solo e o rendimento de soja, milho, feijão e arroz em plantio direto. Scientia Agricola Piracicaba, v.57, n.1, p.97-104, 2000

LANGDALE, G.W. et al. Cropping frequencies to sustain longterm conservation tillage systems. Soil Science Society of America Journal, Madison, v.54, n.1, p.193-198, 1990.

PAULETTI, V. et al. Rendimento de grãos de milho e soja em uma sucessão de culturas de oito anos sob diferentes sistemas de manejo de solo e de rotação. Ciência Rural, Santa Maria v.33, n.3, p.491-495, 2003.

PEDERSEN, P.; LAUER, J.G. Corn and soybean response to rotation sequence, raw spacing, and tillage system. Agronomy Journal, Madison, v.95, n.1, p.965-971, 2003

ROMAN, E.S.; VELLOSO, J.A.R. de O. Controle cultural, coberturas mortas e alelopatia em sistemas conservacionistas In: EMBRAPA. Centro Nacional de Pesquisa de Trigo (Passo
Fundo, RS). Plantio direto no Brasil. Passo Fundo: EMBRAPA-CNPT/FUNDACEP FECOTRIGO/Fundação ABC/ Aldeia Norte, 1993. p.77-84.

RUEDELL, J. Plantio direto na região de Cruz Alta. Cruz Alta: FUNDACEP FECOTRIGO, 1995. 134p.

SANTOS, H.P. dos et al. Efeitos de métodos de preparo de solo no inverno e de rotação de culturas no rendimento de grãos de soja. Pesquisa Agropecuária Gaúcha, Porto Alegre, v.7, n.1, p.62-76, 2001

SANTOS, H.P. dos et al. Efeitos de culturas de inverno e de sistema de rotação de culturas sobre algumas características da soja. Pesquisa Agropecuária Brasileira, Brasília, v.32, n.11, p.1141-1146, 1997.

SANTOS, H.P. dos et al. Efeito de culturas de inverno em plantio direto sobre a soja cultivada em rotação de culturas. Pesquisa Agropecuária Brasileira, Brasília, v.33, n.3, p.289295, 1998

SANTOS, H.P. dos; REIS, E.M. Efeitos de culturas de inverno sobre o rendimento de grãos e sobre a estatura de plantas da soja. Pesquisa Agropecuária Brasileira, Brasília, v.26, n.5, p.729-735, 1991 .

SANTOS, H.P. dos; REIS, E.M. Rotação de culturas. In: SANTOS, H.P. dos; REIS, E.M. Rotação de culturas em plantio direto. Passo Fundo: Embrapa Trigo, 2001. Cap. 1, p.11-132.

SANTOS, H.P. dos; ROMAN, E.S. Efeitos de culturas de inverno e rotações sobre a soja cultivada em sistema plantio direto Pesquisa Agropecuária Gaúcha, Porto Alegre, v.7., n.1, p.59-68, 2001

SANTOS, H.P. dos et al. Plantio direto versus convencional: efeito na fertilidade do solo e no rendimento de grãos de culturas em rotação com cevada. Revista Brasileira de Ciência de Solo, Campinas, v.19, n.3, p.449-454, 1995

SANTOS, H.P. dos; TOMM, G.O. Disponibilidade de nutrientes e teor de matéria orgânica em função de sistemas de cultivo e de manejo de solo. Ciência Rural, Santa Maria, v.33, n.3, p.477486, 2003

SIDIRAS, N. et al. Influência de diferentes sistemas de preparo do solo na variação da umidade e rendimento de grãos de soja, em Latossolo Roxo distrófico (Oxisol). Revista Brasileira de Ciência de Solo, Campinas, v.7, n.1, p.103-106, 1983.

SOCIEDADE BRASILEIRA DE CIÊNCIA DO SOLO. Núcleo Regional Sul. Comissão de Química e Fertilidade do Solo. Manual de adubação e de calagem para os estados do Rio Grande do Sul e de Santa Catarina. 10.ed. Porto Alegre,Comissão de Química e Fertilidade do solo, 2004. 394p.

STATISTICAL ANALYSIS SYSTEMS INSTITUTE. SAS system for Microsoft Windows, version 8.2. Cary, 554p. 2003.

STRECK, E.V. et al. Solos do Rio Grande do Sul. Porto Alegre: EMATER/RS, Universidade Federal do Rio Grande do Sul, 2002. 126p.

YUSUF, R.I. et al. Growth analysis of soybean under no-tillage and conventional tillage systems. Agronomy Journal, Madison, v.91, n.6, p.928-933, 1999. 